\title{
Profil fraktur diafisis femur periode Januari 2013 - Desember 2014 di RSUP Prof. Dr. R. D. Kandou Manado
}

\author{
${ }^{1}$ Ezra A. W. Wattie \\ ${ }^{2}$ Alwin Monoarfa \\ ${ }^{2}$ Hilman P. Limpeleh
}

\author{
${ }^{1}$ Kandidat Skripsi Fakultas Kedokteran Universitas Sam Ratulangi Manado \\ ${ }^{2}$ Bagian Bedah Fakultas Kedokteran Universitas Sam Ratulangi Manado \\ Email: ewattie_11_224@yahoo.co.id
}

\begin{abstract}
The incidence of femoral diaphysis fracture has increased recently. The most common cause of this fracture is motor vehicle accident. Femoral diaphysis fracture can be accompanied by multiple fractures (fractures of other bones) which depends on the cause. This study aimed to determine the distribution of the femoral diaphysis fracture cases by age, gender, anatomical location of the fracture, type of fracture (open and closed), and the management (adults and children). This was a descriptive retrospective study. Samples were all patients with femoral diaphysis fractures treated in the period of January 2013 to December 2014. Data of the patients were obtained from the medical records of Surgery Department based on the variables. The age was categoried of: children (0-11), teenagers (12-17), young adults (18-44), older adults (45-64), and elderly (65+). The anatomical location of the fracture consisted of $1 / 3$ proximal, $1 / 3$ medial, and $1 / 3$ distal. The management of adult patients were ORIF (plate and screw), ORIF (screw and wiring), and ORIF (Kuntscher nail). The management of children was Hamilton-Russell traction, Bryan traction, and distal skeletal traction. The results showed that there were 45 patients in the 2year period consisting of 29 (64.5\%) patients in 2013 and 16 (35.5\%) patients in 2014. The gender which dominated these cases was male with 26 patients (57.8\%). Females were only 10 patients (22.2\%). There were 9 patients (20.0\%) without ae and sex categories. Among males, the fracture occurred in children (2 patients, 4.4\%), adolescents (8 patients, 21.7\%), young adults (10 patients, $22.2 \%$ ), older adults (5 patients, $11.1 \%$ ), and the elderly (1 patient, $2.2 \%$ ) The incidence in women increased in older adults (5 patients, 11.1\%). According to the anatomic location of the fracture, the highest incidence was in the $1 / 3$ medial of the femoral diaphysis (30 patients, 66.6\%). The most common type of fracture based on the exposure to the external environment is closed fractures (27 patients, 60\%). The distribution of the cases based on the operative management of adult patients did not provide any meaningful information because there had been a lot of patients (31 patients, $68.8 \%$ of the existing data) that did not include the type of operative management. The case distribution based on the treatment of children showed no traction. Conclusion: There was an increase of the femoral diaphysis cases which was more significant in males than in females with the growing incidence in young adult males. While in women, there was a slight increase in the incidence in older adults.
\end{abstract}

Keywords: femoral diaphysis fracture

\begin{abstract}
Abstrak: Angka kejadian meningkat pada fraktur diafisis femur dengan penyebab tersering kecelakaan kendaraan bermotor. Fraktur diafisis femur bisa disertai dengan fraktur multipel (fraktur pada tulang-tulang yang lain) tergantung dengan penyebabnya. Penelitian ini bertujuan untuk mengetahui distribusi kasus fraktur diafisis femur berdasarkan umur, jenis kelamin, lokasi anatomis fraktur, jenis fraktur (terbuka dan tertutup), dan penatalaksanaan (dewasa dan anak-anak). Jenis penelitian ini deskriptif retrospektif. Sampel ialah semua pasien fraktur diafisis femur yang dirawat pada periode Januari 2013 - Desember 2014. Data pasien diambil dari PPDS Ilmu Bedah berdasarkan variabel-variabel yang akan diteliti. Umur yaitu berdasarkan kategori anak-anak (011), remaja (12-17), dewasa muda (18-44), dewasa tua (45-64), dan lanjut usia (65+). Lokasi
\end{abstract}


anatomis fraktur yaitu terdiri dari 1/3 proximal, 1/3 medial, dan 1/3 distal. Penatalaksanaan pada pasien dewasa yaitu ORIF (plate \& screw), ORIF (screw \& wiring), dan ORIF (Kuntscher nail). Tatalaksana pada anak-anak yaitu traksi Hamilton-Russel, traksi Bryant, dan traksi skeletal distal. Hasil penbelitian memperlihatkan terdapat 45 Pasien dalam periode 2 tahun: 29 (64,5\%) pasien pada tahun 2013 dan 16 (35,5\%) pasien pada tahun 2014. Jenis kelamin yang mendominasi kasus ialah laki-laki yaitu 26 pasien (57,8\% dari keseluruhan data). Pada perempuan diperoleh 10 pasien (22,2\% dari keseluruhan data). Terdapat 9 pasien $(20,0 \%)$ yang tidak tercantum umur dan jenis kelamin. Pada laki-laki, fraktur ditemukan pada: anak-anak (2 pasien, 4,4\%), remaja (8 pasien, 21,7\%), dewasa muda (10 pasien, 22,2\%), dewasa tua (5 pasien, 11,1\%), dan usia lanjut (1 pasien, 2.2\%). Angka kejadian pada perempuan meningkat pada kategori usia dewasa tua (5 pasien, $11,1 \%)$. Pada distribusi pasien menurut lokasi anatomis fraktur, insiden tertinggi pada lokasi 1/3 medial diafisis femur (30 pasien, 66.6\%). Jenis fraktur tersering berdasarkan ada atau tidaknya paparan lingkungan eksternal ialah fraktur tertutup (27 pasien, 60\%). Distribusi kasus berdasarkan tatalaksana operatif pada pasien dewasa tidak memberikan info yang bermakna oleh karena terdapat banyak pasien (31 pasien, 68,8\%) yang tidak mencantumkan jenis tatalaksana operatif. Pada distribusi kasus berdasarkan tatalaksana pada anak-anak tidak ditemukan pasien yang menjalani traksi. Simpulan: Terdapat peningkatan kasus fraktur diafisis femur yang bermakna pada laki-laki dibanding perempuan dengan insiden meningkat pada laki-laki dewasa muda. Pada perempuan, terjadi sedikit peningkatan insiden pada usia dewasa tua.

Kata kunci: fraktur diafisis femur

Femur atau tulang paha adalah tulang terberat, terpanjang, dan terkuat yang terdapat di tubuh kita. Femur di tutupi oleh lapisan otot-otot yang tebal oleh karena itu butuh kekuatan tekanan yang besar pada femur untuk menyebabkan fraktur. ${ }^{1-3}$

Pada orang yang telah lanjut usia atau penderita osteoporosis, kekuatan tekanan yang ringan pada femur bisa menyebabkan fraktur. ${ }^{1}$ Fraktur femur yang disebabkan oleh kekuatan tekanan yang tinggi biasanya terjadi oleh karena jatuh dari ketinggian dan kecelakaan kendaraan bermotor. Fraktur femur juga bisa dicetus oleh berbagai macam penyakit contohnya Paget's disease, tumor, kanker dan kelainan metabolisme. $^{2}$

Fraktur femur bervariasi tergantung lokasi dan gambaran fraktur. Fraktur femur bisa atau tanpa dislokasi tulang dan bisa berupa fraktur tertutup (tidak menembus kulit atau tidak terbuka dengan lingkungan eksternal) dan fraktur terbuka (Menembus kulit dan terbuka dengan lingkungan eksternal). $^{2-4}$ Menurut garis frakturnya, patah tulang dibagi menjadi fraktur komplit atau inkomplit (termasuk fisura atau greenstick fracture), transversa, oblik, spiral, kompresi, simple, kominutif, segmental, kupu-kupu, dan impaksi (termasuk impresi dan inklavasi).3
Terdapat beberapa jenis fraktur femur berdasar lokasi anatomis yaitu fraktur leher femur, fraktur trokanter femur, fraktur subtrokanter femur, fraktur diafisis femur, fraktur suprakondilus femur dan fraktur kondilus femur. $^{2-4}$ Pada penelitian ini, perhatian hanya akan difokuskan pada fraktur diafisis femur.

Insidensi fraktur diafisis femur pada orang dewasa umur 20 tahun ke- atas telah diteliti di Stockholm, Swedia. Data diambil dari 277 rekam medik dan juga dengan penentukan insidensi sub-populasi dari 139 kasus dengan menggunakan metode alternatif. Insiden menurun dari umur 20 tahun sampai pada usia pertengahan (40-60 tahun) dan kembali naik pada usia 60 tahun ke atas. Peningkatan insiden berdasarkan umur lebih nyata pada wanita dan pada fraktur yang disebabkan oleh trauma sedang. Pada tahun 1972-1981, insidensi fraktur diafisis femur yang disebabkan oleh trauma sedang bertambah $10 \%$ setiap tahunnya pada wanita yang berumur 75 tahun ke atas. ${ }^{5}$

Pada tahun 1998-2004 di Swedia terdapat 6409 pasien dengan fraktur diafisis femur atau 10 per 100.000 orang per tahun. ${ }^{6}$ Insiden fraktur diafisis femur yang disebabkan oleh trauma berat tinggi pada laki-laki dibawah 40 tahun dan sering 
disebabkan oleh kecelakaan kendaraan bermotor. Pada laki-laki di atas 40 tahun yang mengalami fraktur diafisis femur sering disebabkan oleh trauma sedang (contohnya jatuh saat melakukan aktivitas). ${ }^{7}$

Pada data yang diperoleh dari Maryland Health Services Cost Review Commission pada tahun 1990-1996 terdapat 1485 kasus fraktur diafisis femur akut pada pasien yang kurang dari 18 tahun. Presentase fraktur diafisis femur pada anak-anak setiap tahunnya mencapai 19.15 per 100.000 . Jika dilihat berdasarkan umur terdapat distribusi bimodal yaitu pada usia 2 tahun dan 17 tahun. Penyebab fraktur diafisis femur pada kebanyakan anak-anak yang berumur dibawah 6 tahun adalah jatuh, pada anak-anak 6 sampai 9 tahun adalah kecelakaan lalu lintas dan kecelakaan pejalan kaki, sedangkan pada anak-anak usia remaja sebagian besar adalah kecelakaan lalu lintas. ${ }^{8}$

Data mengenai distribusi kasus berdasarkan umur, jenis kelamin, lokasi fraktur pada diafisis, jenis fraktur, dan penatalaksanaan dari semua pasien yang mengalami fraktur diafisis femur setiap tahunnya bisa menjadi acuan yang penting untuk penelitian selanjutnya. Pada penelitian ini gambaran fraktur diafisis femur diteliti pada periode waktu tahun 2013-2014 atau dengan lama waktu dua tahun penuh.

\section{METODE PENELITIAN}

Penelitian ini bersifat deskriptif retrospektif. Lama penelitian adalah 2 bulan. Semua data pasien diambil dari catatan-catatan PPDS Ilmu Bedah. Umur yaitu berdasarkan kategori anak-anak (011), remaja (12-17), dewasa muda (18-44), dewasa tua (45-64), dan lanjut usia (65+). Lokasi anatomis fraktur yaitu terdiri dari 1/3 proximal, 1/3 medial, dan 1/3 distal. Penatalaksanaan pada pasien dewasa yaitu ORIF (plate \& screw), ORIF (screw \& wiring), dan ORIF (Kuntscher nail). Tatalaksana pada anak-anak yaitu traksi Hamilton-Russel, traksi Bryant, dan traksi skeletal distal. Data-data yang kemudian diolah dan dipaparkan dalam bentuk tabel. Selanjutnya dilakukan analisis deskriptif terhadap semua data yang diperoleh.

\section{HASIL PENELITIAN}

Pada penelitian ini, dari keseluruhan pasien yang didapat ada beberapa pasien yang tidak mencantumkan data pada masing-masing variabel. Persentase ditulis berdasarkan jumlah keseluruhan data yang tersedia.

\section{Angka kejadian}

Pada bulan Januari 2013 - Desember 2014 didapatkan 45 pasien fraktur diafisis femur di RSUP Prof. Dr. R. D. Kandou Manado. Pada penelitian ini diperoleh 29 (64,5\%) pasien pada tahun 2013 dan 16 (35,5\%) pasien pada tahun 2014 (Tabel 1).

Tabel 1. Angka Kejadian Fraktur Diafisis Femur

\begin{tabular}{ccc}
\hline $\begin{array}{c}\text { Periode } \\
\text { Waktu }\end{array}$ & Jumlah & Persentase \\
\hline 2013 & 29 & $64,5 \%$ \\
\hline 2014 & 16 & $35,5 \%$ \\
\hline
\end{tabular}

\section{Jenis kelamin}

Fraktur diafisis femur diteliti berdasarkan distribusi jenis kelamin pada 45 kasus dalam periode waktu tahun 2013-2014 di RSUP. Prof. DR. R. D. Kandou Manado. Didapatkan peningkatan insiden yang bermakna pada laki-laki yaitu 26 pasien dengan persentase 57,8\% dari 45 data yang ada. Pada perempuan hanya didapati 10 pasien dengan persentase $22,2 \%$ dari data yang ada. Terdapat 9 (20\% dari 45 data) pasien yang tidak dicantumkan jenis kelamin dan umur.

Tabel 2. Distribusi kasus berdasarkan jenis kelamin

\begin{tabular}{ccc}
\hline $\begin{array}{c}\text { Jenis } \\
\text { Kelamin }\end{array}$ & Jumlah & Persentase \\
\hline \multicolumn{1}{c}{ Laki-laki } & 26 & $57,8 \%$ \\
\hline Perempuan & 10 & $22,2 \%$ \\
\hline $\begin{array}{l}\text { Tidak } \\
\text { dicantumkan }\end{array}$ & 9 & $20,0 \%$ \\
\hline
\end{tabular}




\section{Umur}

Telah diketahui bahwa jumlah keseluruhan pasien adalah 45 pasien tetapi jumlah keseluruhan kasus yang mencantumkan jenis kelamin dan umur baik laki-laki maupun perempuan hanya 36 pasien (terdiri dari 26 pasien laki-laki dan 10 pasien perempuan). Yang dipaparkan pada tabel hanya 36 pasien yang mencantumkan umur dan jenis kelamin. Sisanya ada 9 (20.0\%) pasien yang tidak mencantumkan umur dan jenis kelamin (Tabel 3 dan 4).

Pada 26 pasien laki-laki hanya didapatkan 2 pasien fraktur pada anak lakilaki (4,4\% dari 45 kasus) dan insiden meningkat pada laki-laki remaja yaitu 8 pasien (21.7\% dari 45 kasus). Pada pasien laki-laki dewasa muda terjadi peningkatan insiden yang bermakna. Pada kategori ini didapatkan 10 pasien fraktur (22.2\% dari 45 kasus). Pada laki-laki dewasa tua insiden menurun menjadi 5 pasien $(11,1 \%)$. Pada laki-laki usia lanjut didapati 1 kasus (2.2\%).

Pada pasien perempuan hanya didapati 10 kasus fraktur diafisis femur yang terdiri dari 2 kasus pada remaja perempuan (4,4\% dari 45 kasus), 1 kasus pada perempuan dewasa muda (2,2\% dari 45 kasus), 5 kasus pada perempuan dewasa tua $(11,1 \%$ dari 45 kasus), dan 1 kasus (2,2\% dari 45 kasus) kasus pada perempuan lanjut usia.

Terdapat 1 pasien (2,2\%) yang mencantumkan jenis kelamin perempuan tetapi umurnya tidak dicantumkan. Tidak terdapat pasien perempuan dalam kategori anak-anak pada hasil yang diperoleh.

Tabel 3. Distribusi kasus berdasarkan umur pada laki-laki

\section{Laki-laki}

\begin{tabular}{lll}
\hline Umur & Jumlah & Persentase \\
\hline $0-11$ tahun & 2 & $4,4 \%$ \\
\hline $12-17$ tahun & 8 & $21,7 \%$ \\
\hline $18-44$ tahun & 10 & $22,2 \%$ \\
\hline $\begin{array}{l}45-64 \text { tahun } \\
\text { 65 tahun }\end{array}$ & 5 & $11,1 \%$ \\
keatas & 1 & $2,2 \%$ \\
\hline
\end{tabular}

Tabel 4. Distribusi kasus berdasarkan umur pada perempuan

\section{Perempuan}

\begin{tabular}{ccc}
\hline Umur & Jumlah & Persentase \\
\hline $0-11$ tahun & 0 & $0 \%$ \\
\hline $12-17$ tahun & 2 & $4,4 \%$ \\
\hline $18-44$ tahun & 1 & $2,2 \%$ \\
\hline $45-64$ tahun & 5 & $11,1 \%$ \\
\hline $\begin{array}{c}65 \text { tahun } \\
\text { keatas }\end{array}$ & 1 & $2,2 \%$ \\
\hline $\begin{array}{c}\text { Tidak } \\
\text { dicantumkan }\end{array}$ & 1 & $2,2 \%$ \\
\hline
\end{tabular}

\section{Lokasi anatomis fraktur diafisis femur}

Tabel 5. Distribusi kasus berdasarkan lokasi anatomis fraktur pada laki-laki

\section{Laki-laki}

\begin{tabular}{lccc}
\hline Umur & $\begin{array}{c}1 / 3 \\
\text { Proximal }\end{array}$ & $1 / 3$ Medial & $1 / 3$ Distal \\
\hline $0-11$ tahun & - & $1(2.2 \%)$ & $1(2.2 \%)$ \\
$12-17$ tahun & $1(2.2 \%)$ & $5(11.1 \%)$ & $2(4.4 \%)$ \\
$18-44$ tahun & $1(2.2 \%)$ & $8(17.7)$ & - \\
$45-64$ tahun & - & $4(8.8 \%)$ & - \\
$>65$ tahun & - & - & $1(2.2 \%)$ \\
Total & $2(2.2 \%)$ & $18(40 \%)$ & $4(8.8 \%)$ \\
\hline
\end{tabular}


Jurnal e-Clinic (eCl), Volume 4, Nomor 1, Januari-April 2016

Tabel 6. Distribusi kasus berdasarkan lokasi anatomis fraktur pada perempuan

Perempuan

\begin{tabular}{cccc}
\hline Umur & $1 / 3$ Proximal & $1 / 3$ Medial & $1 / 3$ Distal \\
\hline $0-11$ tahun & - & - & - \\
$12-17$ tahun & - & $1(2,2 \%)$ & $1(2,2 \%)$ \\
$18-44$ tahun & - & $1(2,2 \%)$ & \\
45-64 tahun & - & $2(4,4 \%)$ & $3(6,6 \%)$ \\
$>65$ tahun & $1(2,2 \%)$ & - & - \\
Tidak & $1(2,2 \%)$ & - & - \\
dicantumkan & $2(4,4 \%)$ & $4(8.8 \%)$ & $4(8,8 \%)$ \\
Total & & &
\end{tabular}

\section{Total Keseluruhan}

Terdapat 9 pasien yang tidak dicantumkan jenis kelamin dan umur tetapi dicantumkan lokasi anatomis fraktur. Kasus fraktur didominasi oleh fraktur diafisis femur 1/3 medial (30 pasien, 66,6\% dari 45 kasus).

Tabel 7. Distribusi kasus berdasarkan lokasi anatomis fraktur pada keseluruhan pasien

\begin{tabular}{lcc}
\hline $\begin{array}{l}\text { Lokasi } \\
\text { Fraktur }\end{array}$ & Jumlah & Persentase \\
\hline 1/3 Proximal & 5 & $11,1 \%$ \\
1/3 Medial & 30 & $66,6 \%$ \\
1/3 Distal & 8 & $17,7 \%$ \\
Tidak & 2 & $4,4 \%$ \\
dicantumkan & 2 & \\
\hline
\end{tabular}

Pada laki-laki terdapat 1 kasus (2,2\%) fraktur femur 1/3 medial pada anak-anak, 5 kasus (11,1\%) pada remaja, 8 kasus $(17,7 \%)$ pada dewasa muda, dan 4 kasus
(8.8\%) pada dewasa tua. Sedangkan pada perempuan terdapat 1 kasus (2.2\%) pada remaja, 1 kasus (2.2\%) pada dewasa muda, dan 2 kasus (4.4\%) pada dewasa tua.

Fraktur femur 1/3 proximal terjadi pada laki-laki remaja (1 pasien, 2.2\%), lakilaki dewasa tua (1 pasien, 2.2\%), dan perempuan lanjut usia (1 pasien, 2.2\%). Terdapat 1 kasus fraktur femur 1/3 proximal pada perempuan yang tidak mencantumkan usia dan 1 kasus pada pasien yang tidak mencantumkan usia dan jenis kelamin. Dengan demikian terdapat 5 kasus fraktur femur 1/3 proximal.

Pada penelitian ini, terdapat 8 kasus $(17,7 \%)$ fraktur femur $1 / 3$ distal. Pada lakilaki terdapat 1 kasus (2,2\%) pada anak, 2 kasus (4,4\%) pada remaja, 1 kasus (2,2\%) pada usia lanjut. Pada perempuan terdapat 1 kasus (2,2\%) fraktur femur $1 / 3$ distal pada remaja, dan 3 kasus (6,6\%) pada dewasa tua.

\section{Jenis fraktur berdasarkan tingkat pemaparan tulang dengan lingkungan eksternal}

Tabel 8. Distribusi kasus berdasarkan tingkat pemaparan fraktur dengan lingkungan eksternal pada laki-laki

\begin{tabular}{ccccccc}
\hline $\begin{array}{c}\text { Laki-laki } \\
\text { (tahun) }\end{array}$ & Tertutup & Gr I & Gr II & Gr IIIa & Gr IIIb & Gr IIIc \\
\hline $0-11$ & - & $1(2,2 \%)$ & - & - & - & - \\
$12-17$ & $4(8,8 \%)$ & - & $1(2,2 \%)$ & - & - & - \\
$18-44$ & $6(13,3 \%)$ & - & $2(4,4 \%)$ & - & - & - \\
$45-64$ & $3(6,6 \%)$ & - & - & - & - & - \\
$>65$ & - & - & - & - & - & - \\
Total & $13(28,7 \%)$ & $1(2,2 \%)$ & $3(6,6 \%)$ & - & - & - \\
\hline
\end{tabular}


Wattie, Monoarfa, Limpeleh: Profil fraktur diafisis femur ...

Tabel 9. Distribusi kasus berdasarkan tingkat pemaparan fraktur dengan lingkungan eksternal pada perempuan

Perempuan

\begin{tabular}{ccrrccc}
\hline $\begin{array}{l}\text { Umur } \\
\text { (tahun) }\end{array}$ & Tertutup & Gr I & Gr II & Gr IIIa & Gr IIIb & Gr IIIc \\
\hline $0-11$ & - & - & - & - & - & - \\
$12-17$ & $1(2,2 \%)$ & - & - & - & - & - \\
$18-44$ & - & - & - & - & - & - \\
$45-64$ & $3(6,6 \%)$ & - & - & - & - & - \\
$>65$ & $1(2,2 \%)$ & - & - & - & - & - \\
Total & $5(11,1 \%)$ & - & - & - & - & - \\
\hline
\end{tabular}

\section{Total keseluruhan}

Termasuk 9 pasien yang tidak mencantumkan jenis kelamin dan umur tetapi mencantumkan jenis fraktur berdasarkan tingkat pemaparan tulang dengan lingkungan eksternal.

Tabel 10. Distribusi kasus berdasarkan tingkat pemaparan fraktur pada semua pasien

\begin{tabular}{lcc}
\hline Jenis fraktur & Jumlah & Persentase \\
\hline Tertutup & 27 & $60,0 \%$ \\
Terbuka Grade I & 1 & $2,2 \%$ \\
Terbuka Grade II & 3 & $6,6 \%$ \\
Terbuka Grade IIIa & - & - \\
Terbuka Grade IIIb & - & - \\
Terbuka Grade IIIc & - & - \\
Terbuka (Grade tidak & 2 & $4,4 \%$ \\
dicantumkan) & & $26,6 \%$ \\
Tidak dicantumkan & 12 & \\
\hline
\end{tabular}

Jumlah kasus diteliti dari jenis fraktur berdasarkan tingkat pemaparan tulang dengan lingkungan eksternal. Tabel 8 dan Tabel 9 memaparkan distribusi kasus berdasarkan umur dan jenis kelamin agar bisa dilihat dengan lebih jelas. Dapat dilihat bahwa fraktur tertutup memegang insidensi tertinggi dari semua jenis fraktur dengan insidensi yang meningkat pada laki-laki dewasa muda. Pada laki-laki, distribusi kasus fraktur tertutup terdapat pada 4 pasien remaja $(8,8 \%), 6$ pasien dewasa muda (13,3\%), dan 3 pasien dewasa tua (6,6\%). Pada perempuan distribusi kasus fraktur tertutup terdapat pada 1 pasien remaja (2,2\%), 3 pasien dewasa tua (6,6\%), 1 pasien lanjut usia (2,2\%). Terdapat 9 pasien $(20,0 \%)$ yang mengalami fraktur tertutup tetapi tidak mencantumkan umur dan jenis kelamin.

Untuk fraktur terbuka grade I hanya diperoleh 1 (2,2\%) kasus pada anak lakilaki. Sedangkan fraktur terbuka grade II hanya didapati 1 (2,2\%) kasus pada remaja laki-laki dan 2 (4,4\%) kasus pada laki-laki dewasa muda. Pada penelitian ini tidak ditemukan fraktur terbuka grade III. Dapat kita lihat bahwa terdapat juga 2 (4,4\%) kasus fraktur terbuka yang tidak dicantumkan grade dan 12 (26,6\%) kasus yang sama sekali tidak mencantumkan jenis fraktur.

\section{Penatalaksanaan Operatif Pada Pasien Dewasa}

Distribusi kasus fraktur diafisis femur diteliti berdasarkan tindakan pembedahan yang dilaksanakan pada masing-masing kasus. Dari 45 kasus hanya ditemukan 4 (8.8\%) orang pasien yang menjalani tindakan ORIF (plate and screw), 1 (2.2\%) orang pasien dengan tindakan ORIF (screw and wiring), dan 4 (8.8\%) orang dengan tindakan ORIF (Kuntscher nail). Ada 5 (11.1\%) pasien yang tidak dicantumkan jenis tindakan operatif spesifik dan 31 pasien (68.8\%) yang sama sekali tidak dicantumkan jenis tindakan operatif yang dilakukan. 
Tabel 11. Distribusi kasus berdasarkan tatalaksana operatif pada pasien dewasa

\begin{tabular}{lccc}
\hline $\begin{array}{l}\text { Penatalaksaan Operatif } \\
\text { dewasa }\end{array}$ & pada & Jumlah & Persentase \\
\hline ORIF (plate \& screw) & 4 & $8.8 \%$ \\
ORIF (screw \& wiring) & 1 & $2.2 \%$ \\
ORIF (Kuntscher nail) & 4 & $8.8 \%$ \\
ORIF (jenis tindakan tidak & 5 & $11.1 \%$ \\
dicantumkan) & & 31 & $68.8 \%$ \\
\hline
\end{tabular}

\section{Penatalaksanaan Fraktur Diafsisis Femur Pada Anak-anak.}

Penatalaksanaan fraktur diafisis femur pada anak dibagi menjadi 3 yaitu traksi Bryant, traksi Hamilton-Russell, dan skeletal traksi distal Pada hasil penelitian, tidak ditemukan adanya pasien anak-anak yang berusia 0-11 tahun yang menjalankan traksi. Pada 45 data yang ada, hanya didapati 2 pasien anak laki-laki yang termasuk dalam kategori 0-11 tahun yang tidak dicantumkan tatalaksana.

Tabel 12. Distribusi kasus berdasarkan tatalaksana pada anak-anak

\begin{tabular}{lcc}
\hline Penatalaksaan pada anak & Jumlah & Persentase \\
\hline $\begin{array}{l}\text { Traksi Bryant } \\
(0-1 \text { tahun })\end{array}$ & 0 & $0 \%$ \\
$\begin{array}{l}\text { Traksi Hamilton-Russell } \\
(2-10 \text { tahun })\end{array}$ & 0 & $0 \%$ \\
$\begin{array}{l}\text { Skeletal traksi distal } \\
(10 \text { tahun keatas) }\end{array}$ & 0 & $0 \%$ \\
\hline
\end{tabular}

\section{BAHASAN}

Hasil penelitian menunjukan bahwa terdapat 45 kasus fraktur diafisis femur di RSUP. Prof. DR. R. D. Kandou Manado pada periode Januari 2013-Desember 2014 atau sama dengan lama waktu 2 tahun. Pada penelitian ini terdapat 4 variabel yang menonjol yaitu jenis kelamin, umur, lokasi anatomis fraktur, dan jenis fraktur berdasarkan pemaparan dengan lingkungan eksternal.

Jenis kelamin yang paling mendominasi angka kejadian adalah lakilaki. Terdapat 26 pasien laki-laki (57,8\% dari 45 kasus) dibanding dengan perempuan yang hanya 10 pasien (22,2\% dari 45 kasus). Distribusi kasus berdasarkan umur diteliti dari 36 kasus. Pada laki-laki, insiden terendah terdapat pada anak-anak (2 pasien, 4,4\%) dan meningkat pada usia remaja (8 pasien, $21,7 \%$ ) sampai memuncak pada dewasa muda (10 pasien, 22,2\%). Insiden kemudian kembali turun pada dewasa tua (5 pasien, 11,1\%) dan usia lanjut (1 pasien, $2,2 \%)$. Pada perempuan terjadi peningkatan pada usia dewasa tua (5 pasien, 11,1\%).

Pada distribusi pasien fraktur diafisis femur berdasarkan lokasi anatomis fraktur didapati peningkatan insiden yang bermakna pada pasien-pasien dengan fraktur diafisis $1 / 3$ medial yaitu 30 pasien (66,6\% dari 45 kasus). Fraktur diafisis 1/3 medial pada laki-laki memuncak pada usia dewasa muda yaitu 8 pasien (17,7\%). Ada juga 8 pasien yang mengalami fraktur femur 1/3 medial tapi tidak mencantumkan umur dan jenis kelamin sehingga tidak dipaparkan dalam tabel. Pada perempuan tidak didapati peningkatan fraktur yang dominan dari masing-masing kategori usia.

Distribusi kasus diteliti pada jenis fraktur berdasarkan tingkat pemaparan tulang dengan lingkungan eksternal. Dapat 
dilihat melalui hasil penelitian bahwa insiden tertinggi terjadi pada fraktur tertutup yaitu 27 pasien (60\%) dari 45 data. Jika menilai distribusi kasus berdasarkan umur dan jenis kelamin, insiden fraktur tertutup tertinggi pada laki-laki dewasa muda yaitu 6 (13,3\%) pasien. Tidak didapati fraktur dengan grade III pada penelitian ini. Pada perempuan tidak didapati jenis fraktur selain fraktur tertutup yaitu 5 (11,1\%) kasus. Pada perempuan diperoleh $1(2,2 \%)$ kasus pada remaja, 3 $(6,6 \%)$ kasus pada dewasa tua, dan 1 $(2,2 \%)$ kasus pada lanjut usia.

Dapat dilihat melalui tabel hasil penelitian bahwa ada 2 (4,4\%) pasien lain yang mengalami fraktur terbuka tetapi jenis spesifik fraktur terbuka tidak dicantumkan. Dan masih ada 12 (26,6\%) pasien yang jenis frakturnya tidak dicantumkan. Distribusi kasus berdasarkan tatalaksana operatif pada pasien dewasa tidak memberikan info yang bermakna oleh karena terdapat banyak pasien (31 pasien, $68,8 \%$ dari data yang ada) yang tidak mencantumkan jenis tatalaksana operatif. Pada distribusi kasus berdasarkan tatalaksana pada anak-anak tidak ditemukan pasien yang menjalani traksi.

\section{SIMPULAN DAN SARAN}

Hasil penelitian menunjukan bahwa terdapat 45 kasus fraktur diafisis femur di RSUP. Prof. DR. R. D. Kandou Manado pada periode Januari 2013-Desember 2014. Pada laki-laki bahwa insiden terjadi dari anak-anak serta meningkat pada remaja sampai memuncak pada dewasa muda dan kembali menurun pada dewasa tua dan usia lanjut. Angka kejadian pada perempuan meningkat pada kategori usia dewasa tua.

Jenis kelamin yang paling mendominasi kasus fraktur diafisis femur adalah laki-laki dengan lokasi tertinggi pada 1/3 medial diafisis femur. Jenis fraktur tersering ialah fraktur tertutup. Penatalaksanaan pada pasien dewasa dan anak-anak kurang memberikan informasi yang dominan.

Terdapat peningkatan kasus fraktur diafisis femur yang bermakna pada lakilaki dibanding perempuan dengan insiden meningkat pada laki-laki dewasa muda sedangkan pada perempuan, terjadi sedikit peningkatan insiden pada usia dewasa tua.

\section{DAFTAR PUSTAKA}

1. Chaffee EE, Greisheimer EM. Basic Physiology and Anatomy (3rd ed). Philadelphia: J. B. Lippincott Company.

2. Schwartz SI, Shires GT, Spencer FC. Principles of Surgery (6th ed). USA: Mc Graw-Hill, 1994.

3. Sjamsuhidajat R, de Jong W. Buku Ajar Ilmu Bedah (3rd ed). Jakarta: EGC, 2007.

4. Apley AG, Solomon L. Prinsip Fraktur. In: Kartini A, editor. Buku Ajar Ortopedi dan Fraktur Sistem Apley (7th ed). Jakarta: Widya Medika, 1995; p. 238.

5. Weiss RJ, Montgomery SM, Al Dabbagh Z, Jansson KA. National Data of 6409 Swedish Inpatients with Femoral Shaft Fractures: Stable Incidence between 1998 and 2004. Injury. 2009;40(3):304-8.

6. Adnan RM, Zia MI, Amin J, et al. Frequency of femoral fractures; comparison in patients less than and more than 40 years of age. Professional Medical Journal. 2012;19:11.

7. Hinton RY, Lincoln A, Crockett MM, Sponseller P, Smith G. Fractures of Femoral Shaft in Children: Incidence, mechanisms, and sociodemographic risk factors. J Bone Joint Surg Am. 1999;81(4):500-9. 